\title{
Speech Production and Perception across the Segment-Prosody Divide: Data - Theory - Modelling
}

The concept of sound segments has traditionally played a central role in the phonetic representation of words. It underlies the development of alphabetic writing systems, of phonetic transcription and of phonemic theory. Other sound aspects, especially pitch, but also energy, voice quality, rhythm have been conceptualized as being superpositioned on segments in a broader frame of syllables and utterances. The segment is associated with the short-time window of opening and closing movements of the vocal tract, and simultaneously, with the differentiation of lexical and propositional meaning, whereas prosodies are generally associated with long-time windows of pitch, energy and voice quality control, and predominantly with attitudinal and expressive utterance meaning, including the functions of attention seeking, intensity signalling, and syntagmatic phrasing. This different substance-meaning duality in sound segments and prosodies accounts for the current dichotomous mainstream research paradigms of sounds and prosodies. The sound-prosody dichotomy has, however, been repeatedly called into question, among others in the Firthian School of Prosodic Analysis, following Firth's seminal article 'Sounds and Prosodies' from 1948, for example in the study of such suprasegmental phenomena as vowel harmony or long articulatory components of, e.g., palatalization, velarization, nasalization, glottalization in the linguistic function of distinctively marking words and morphological structures. Moreover, it has always been bridged in the analysis of lexical stress, where segmental aspects of vowel duration and vowel spectrum, and prosodic aspects of fundamental frequency and energy have jointly been taken into account in a vast array of experimental investigations.

The reliance on linguistic form and phonetic substance in the analysis of sound segments and prosodies reflects the tenets of 20th century structural linguistics, as it relegates the functional aspect of speech communication to a post hoc level. Such a dichotomous formal approach is a useful heuristics to come to grips with the enormous complexity of speech, especially in the initial stages in the investigation of a language. Yet, the formal manifestations, analytically separated as sounds and prosodies, are the joint expression of the manifold communicative functions in speech: semantic, information-structural, expressive and attitudinal. If these functions are taken as the superordinate control variable, the axiomatic formal dichotomy of sounds and prosodies fades away because they interact, with varying weights, in the coding of specific communicative functions. This functional approach to phonetic detail in segmentprosody interaction was the empirical and theoretical theme of two recent plenary talks at the 17th ICPhS in Hong Kong: 'Does Phonetic Detail Guide Situation-Specific Speech Recognition?' by Sarah Hawkins and 'On the Interdependence of Sounds and Prosodies in Communicative Functions’ by Klaus Kohler. They were preceded by papers

\begin{tabular}{ll}
\hline KARGER & ( ) 2011 S. Karger AG, Basel \\
& $0031-8388 / 11 / 0683-0117$ \\
Fax +4161306 1234 & $\$ 38.00 / 0$ \\
E-Mail karger@karger.ch & Accessible online at: \\
www.karger.com & www.karger.com/pho
\end{tabular}


in Journal of the Acoustical Society of America, Journal of Phonetics, and Phonetica:

Niebuhr, O.: Coding of intonational meanings beyond F0: evidence from utterancefinal /t/ aspiration in German. J. acoust. Soc. Am. 124: 1252-1263 (2008).

Hawkins, S.: Roles and representations of systematic fine phonetic detail in speech understanding. J. Phonet. 31: 373-405 (2003).

Local, J.: Variable domains and variable relevance: interpreting phonetic exponents. J. Phonet. 31: 321-339 (2003).

Kohler K.: Communicative functions integrate segments in prosodies and prosodies in segments. Phonetica 68: 26-56 (2011).

Kohler, K.; Niebuhr O.: On the role of articulatory prosodies in German message decoding. Phonetica 68: 57-87 (2011).

On the one hand, these investigations showed systematic phonetic detail in talkin-interaction as well as acoustic effects of segments on pitch patterns and of pitch patterns on segments in the perceptual identification of semantic functions, and, on the other hand, demonstrated the perceptual importance of long phonetic components of, e.g., palatalization that are not linked to a segmentable sound unit but are superimposed as an articulatory prosody on a wider stretch of speech.

We would like to make this sound-prosody relationship the theme of a special issue of Phonetica and raise the central question:

How are sounds and prosodies intertwined, mutually shaping each other, as a reflection of different communicative functions in speech interaction?

The papers we solicit are to take a renewed look in greater breadth and detail at this interweaving of the threads of sounds and prosodies in a tapestry of speech communication in a variety of languages, incorporating all forms of meaning - propositional, attitudinal and expressive. The guiding principles for submissions are as follows:

- Papers present single-language or comparative analyses of new data in a variety of languages that highlight the interdependence of short- and long-time windows of speech production and/or perception in relation to specific communicative functions or

they discuss aspects of the theory of segment-prosody interdependence based on language-specific, typological or universal relations between communicative function and phonetic substance

or

they attempt to model segment-prosody interaction in these function-substance relations, for example in developing algorithms for contextually and situationally adequate high-quality speech synthesis.

- Data can be either experimental or from corpora, unscripted ones in particular, and experimentally collected items of speech need to be functionally and situationally anchored, which rules out the widespread metalinguistic sentence frame of the type 'Say X again.', commonly used in EMMA and EPG data acquisition.

- Potential topics may include:

- $\quad$ segment-prosody interdependence in talk-in-interaction,

- $\quad$ prosodic and segmental properties in the manifestation of speech functions, for example different types of emphasis, in production and perception,

- contribution of vowel spectrum to lexical stress perception, 
- $\quad$ spectral shaping of segments, for example fricatives and plosive releases, in falling or rising f0 contours, and perceptual effects,

- $\quad$ articulatory prosodies in speech reduction, especially of function words, and their importance in speech decoding,

- creation of rhythmic flow by preferred segmental patterns, such as high versus low vowels, rather than the reverse, in flip-flop, sing song, ping-pong, zig zag, wishy washy, or avoidance of phrase-internal obstruent breaks in sonorant stretches, as in thunder and lightning against the semantically obvious *lightning and thunder, or mum and dad, German Mama und Papa, Oma und Opa,

- $\quad$ signalling of tone and intonation in whispered speech

- contribution of segments and prosody to the generation of high-quality speech synthesis and to (online) spoken word recognition.

\section{Editorial Guidelines and Schedule}

The total space available will be a double issue of the Journal. We expect to publish approximately 12 contributions of 12 printed pages each on average. Submissions need to follow the Phonetica style sheet (cf. 'Instructions to Authors' in any recent issue and www.karger.com/electronic_submission) and should include Word and pdf files. The dates of the editing schedule are as follows:

By 28 January, 2012: Submission by e-mail attachment to kjk@ipds.uni-kiel.de of an 800-word abstract, giving title, author(s), affiliation(s), e-mail address of main author.

29 February, 2012: Notification of authors whether the proposed papers have been recommended as potential contributions to the theme by the Editorial Team, and, if so, invitation to submit full versions for review.

By 31 May, 2012: $\quad$ Electronic submission of pdf files as e-mail attachments to kjk@ipds.uni-kiel.de, to be sent out for review.

31 July, 2012: Intimation of final decision about acceptance for publication in the special issue, including reviewers' comments and suggestions for revision. Due to the tight publication schedule only papers requiring minor or moderate revision can be included in the special issue. If major revision is necessary, authors will be encouraged to resubmit for publication in an ordinary issue of Phonetica.

By 20 August, 2012: Submission of final versions in Word and pdf by e-mail attachment tokjk@ipds.uni-kiel.de.

End of 2012:

Publication.

We are looking forward very much to receiving plenty of interesting papers and to compiling an exciting coherent issue of Phonetica on a forward-looking theme.

The Editorial Team

Speech Production and Perception across the

Phonetica 2011;68:117-119 